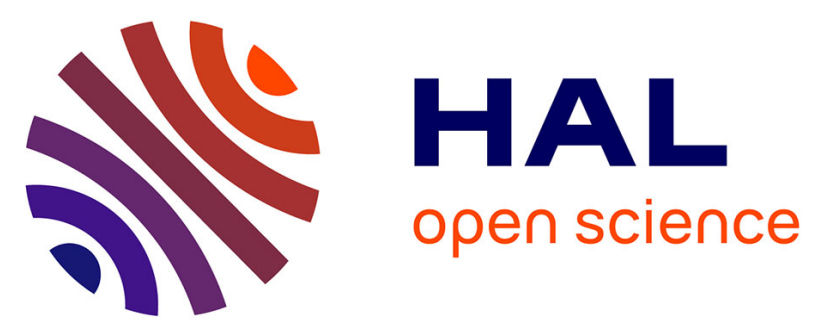

\title{
Environmental exposures related to parental habits in the perinatal period and the risk of Wilms' tumor in children
}

\author{
Anne Notz-Carrere, Paula Rios, Helene Bauer, Gudrun Schleiermacher, \\ Claudia Pasqualini, Cecile Boulanger, Estelle Thébaud, Virginie Gandemer, \\ Isabelle Pellier, Arnauld Verschuur, et al.
}

\section{To cite this version:}

Anne Notz-Carrere, Paula Rios, Helene Bauer, Gudrun Schleiermacher, Claudia Pasqualini, et al.. Environmental exposures related to parental habits in the perinatal period and the risk of Wilms' tumor in children. Cancer Epidemiology, 2020, 66, pp.101706. 10.1016/j.canep.2020.101706 . hal$02887224 \mathrm{v} 2$

\section{HAL Id: hal-02887224 \\ https://hal.science/hal-02887224v2}

Submitted on 2 Mar 2021

HAL is a multi-disciplinary open access archive for the deposit and dissemination of scientific research documents, whether they are published or not. The documents may come from teaching and research institutions in France or abroad, or from public or private research centers.
L'archive ouverte pluridisciplinaire HAL, est destinée au dépôt et à la diffusion de documents scientifiques de niveau recherche, publiés ou non, émanant des établissements d'enseignement et de recherche français ou étrangers, des laboratoires publics ou privés. 


\section{Environmental exposures related to parental habits in the perinatal period and the risk of Wilms' tumor in children.}

Authors: Paula Rios ${ }^{1}$, Hélène Bauer ${ }^{1}$, Gudrun Schleiermacher ${ }^{2}$, Claudia Pasqualini ${ }^{3}$, Cécile Boulanger ${ }^{4}$, Estelle Thebaud ${ }^{5}$, Virginie Gandemer ${ }^{6}$, Isabelle Pellier ${ }^{7}$, Arnauld Verschuur ${ }^{8}$, Hélène Sudour-Bonnange ${ }^{9}$, Aurore Coulomb-l'Hermine ${ }^{10}$, Alexandra Spiegel ${ }^{11}$, Anne NotzCarrere $^{12}$, Christophe Bergeron ${ }^{13}$, Laurent Orsi ${ }^{1}$, Brigitte Lacour ${ }^{1,14}$, Jacqueline Clavel ${ }^{1,14}$

\section{Author affiliations}

${ }^{1}$ CRESS, UMR1153, INSERM, Université de Paris, Villejuif, France

${ }^{2}$ Institut Curie, Paris, France

${ }^{3}$ Gustave Roussy, Université Paris-Saclay, Child and Adolescent Oncology Department, Villejuif, France

${ }^{4}$ CHU Toulouse, Hôpital Purpan, Toulouse, France

${ }^{5}$ CHU de Nantes, Hôtel Dieu, Nantes, France

${ }^{6}$ CHU Hôpital Sud, Université Rennes 1, Rennes, France

${ }^{7}$ CHU d'Angers, Angers, France

${ }^{8}$ AP-HM, Hôpital la Timone, Marseille, France

${ }^{9}$ Centre Oscar Lambret, Lille, France

${ }^{10}$ CHU Armand-Trousseau, Paris, France

${ }^{11}$ CHU de Strasbourg, Hôpital Hautepierre, Strasbourg, France

${ }^{12}$ CHU de Bordeaux, Hôpital Pellegrin, Bordeaux, France

${ }^{13}$ IHOPe, Centre Léon Bérard, Lyon, France

${ }^{14}$ National Registry of Childhood Cancers, APHP, CHU Paul Brousse, Villejuif and CHU de Nancy, France

\section{Corresponding author paula.rios@inserm.fr}

Keywords Wilms' tumor - etiology - pesticides - smoking - alcohol - childhood cancer pregnancy - case-control study 


\section{Abstract}

Introduction: Wilms' tumor is the most frequently diagnosed renal tumor in children. Little is known about its etiology. The aim of this study was to investigate the potential role of specific exposures related to parental habits such as parental smoking, maternal alcohol consumption and the use of household pesticides during pregnancy.

Methods: The ESTELLE study was a nationwide case-control study that included 117 Wilms' tumor cases and 1100 control children from the general French population, frequencymatched by age and gender. Unconditional logistic regression was used to estimate odds ratios and 95\% confidence intervals.

Results: After controlling for matching variables and potential confounders, the maternal use of any type of pesticide during pregnancy was associated with the risk of Wilms' tumor in children (OR 1.6 [95\% CI 1.1 - 2.3]). Insecticides were the most commonly reported type of pesticide and there was a positive association with their use (ORs 1.7 [95\% CI 1.1-2.6]. The association was stronger when they were used more than one a month (OR 1.9 [95\% CI 1.23.0]. Neither maternal smoking during pregnancy nor paternal smoking during preconception/pregnancy was associated with a risk of Wilms' tumor (ORs 1.1[95\% CI 0.71.8] and 1.1 [95\% CI 0.7-1.7], respectively). No association was observed with maternal alcohol intake during pregnancy (OR 1.2 [95\% CI 0.8-2.0]).

Conclusion: Our findings suggest an association between the maternal use of household pesticides during pregnancy and the risk of Wilms' tumor.

\section{Introduction}

Wilms' tumor, or nephroblastoma, is an embryonic tumor that arises in early childhood. It is the most frequently diagnosed renal tumor in children. Overall $80 \%$ of cases are diagnosed before the age of five years[1]. In France, the incidence rate is 7.8 cases per million children aged less than 15 years, which is similar to the incidences reported in other developed countries such as the USA and Germany[1]. The 5-year survival is about 92\%[2]. Wilms' tumor may occur in association with tumor predisposition syndromes such as WAGR syndrome and Beckwith-Wiedemann syndrome, and clinical malformations [3-6].

The etiology of Wilms' tumor is largely unknown. A family history of Wilms' tumor is present in about $1.5 \%$ of all cases [7]. Current knowledge supports the hypothesis that some 
embryonic childhood cancers like Wilms' tumor may have prenatal origins [8] and highlights the need to explore early life exposures, particularly those occurring around conception, and during pregnancy and early childhood. A review of studies published before 2009 [9] has suggested that a maternal history of hypertension during pregnancy, high birth weight, preterm birth and first-born status may be associated with an increased risk of Wilms' tumor.

Parental habits during the perinatal and periconceptional periods are of particular interest since they may predispose to specific environmental exposures with harmful effects on germ cells, and fetal development or very young child development. Among relatively common exposures, smoking [10,11] and alcohol [12] consumption have long been classified as carcinogenic to humans by the International Agency for Research on Cancer (IARC) due to their role in many adult cancers. Components of cigarettes smoke [13] and alcohol have been shown to cross the placenta leading to fetal exposure. To date, studies have yielded heterogeneous results with regard to the associations between parental smoking and maternal alcohol consumption and Wilms' tumor[5,14-19].

Prenatal exposure to pesticides may result from parental use of household pesticides or professional extermination of household pests. The International Agency for Research on Cancer (IARC) has classified more than 20 pesticide chemicals as potential human carcinogens[20,21]. A nationwide survey performed in 2014 by the French Agency for Food, Environmental and Occupational Health Safety (ANSES)[22] has shown that household pesticides were widely used in France and that some individual pesticides such as glyphosate, 2,4 D and malathion, classed as probable or possible carcinogens, were still reported for residential use in 2014. Some pesticides such as pyrethroids and malathion can cross the fetalplacental barrier leading to fetal exposure[23]. Previous studies have investigated the potential associations between parental pesticide exposure in residential [14,15,24], agricultural [25] and occupational [16] settings and the risk of Wilms' tumor. The results are heterogeneous.

The aim of this study was to investigate whether parental smoking, maternal alcohol consumption and the use of household pesticides during pregnancy were associated with the risk of Wilms' tumor in children.

\section{Materials and methods}


The ESTELLE study (Etude Sur les Tumeurs Embryonnaires, Leucémies et Lymphomes de l'Enfant) was conducted in France in 2010-2011. The aim of the nationwide population-based case-control study was to investigate the role of genetic and environmental factors in childhood cancers. The study included cases of Wilms' tumor, leukemia, lymphoma, brain tumor, neuroblastoma and hepatoblastoma. This paper focuses on Wilms' tumor.

Eligible case children were directly identified from the French National Registry of Childhood Cancer (RNCE). Children had to be younger than 15 years and resident in mainland France at the time they were newly diagnosed with Wilms' tumor (Group VIa1. of the International Classification of Childhood Cancer, Third Edition)[26].

The process for inclusion of the case and control children has already been described in detail elsewhere [27]. For ethical reasons, children in palliative care or who had died were not eligible. During the study period, 139 new cases of Wilms' tumor were diagnosed. Children were not included if they had been adopted or if their biological mother was not available because she had died or was absent $(n=2)$, or if their mother did not speak French $(n=6)$ or had a serious psychosocial problem $(n=1)$. Out of the 130 eligible cases, 119 case mothers (91.5\%) were successfully interviewed. Reasons for non-participation included explicit parental refusal $(n=4)$ and contact failure after an appointment $(n=7)$.

Controls were recruited from the general French population among children free from cancer and aged less than 15 years. A first set of allocable telephone numbers was randomly generated. Then, quotas were applied to make the distribution of the controls similar to the distribution of the cases in terms of age and gender. A quota for the number of children aged less than 15 years living in the household was applied in addition with the aim of ensuring that the control group had a distribution similar to that of the general French population, conditionally on age. Numbers were dialed over the two years of the subject recruitment period.

Like the cases, controls were not eligible if they had been adopted or if their biological mother had died or could not speak French. Out of the 1662 eligible households identified, 1421 control mothers (85.5\%) completed the interviews. Reasons for non-participation included explicit refusal $(n=76)$, contact failure after an appointment $(n=107)$ or dropping out during an interview $(\mathrm{n}=58)$.

Because of the particular age distribution of Wilms' tumor cases, this paper focuses on children under 11 years old (98\% of the cases and $77 \%$ of the controls). 


\section{Data collection}

The biological mothers of case and control children responded to a telephone interview conducted by trained interviewers. The interviews were computer-aided and consisted in highly structured questions designed to assess parental lifestyle and the child's environment, socio-demographic characteristics and familial and personal medical history.

The mothers were asked whether they had smoked cigarettes around pregnancy with the index child (three months before pregnancy and in each trimester of pregnancy), and, if so, the average number of cigarettes smoked daily. They were also asked about paternal cigarette smoking in the three months before or during pregnancy. In order to validate the maternal responses with regard to paternal exposures, a subset of fathers were also questioned about their smoking habits. Further questions addressed the maternal alcohol intake during pregnancy.

With regard to pesticide exposures, the mothers were asked about their use of chemical pesticides in the three months prior to conception, during pregnancy and after birth. Specific questions addressed whether the mother had used herbicides, fungicides or insecticides, and where they were used (indoors, outdoors, on pets). If the mother had used pesticides, she was asked how often during the relevant period. Further questions addressed whether there had been any professional domestic pest control treatments.

\section{Data management}

The parents were considered smokers if they had smoked at least one cigarette during the relevant period. Binary variables for smoking were created. The number of cigarettes smoked was classified as follows: 0 ; $<3$; 3-5 and $\geq 6$ cigarettes per day (CPD) for the mothers during pregnancy and $0 ; 1-9 ; 10-19$ and $\geq 20$ CPD for the fathers during the preconception period. The categories were based on the tertiles of consumption reported by the control parents who smoked. The joint effect of maternal and paternal smoking was also analyzed (neither parent, only mother, only father, both parents). Lastly, we assessed smoking exposures in all the categories by time window (three months before the index pregnancy and during pregnancy).

The mothers were considered to have consumed alcohol during pregnancy if they had drunk wine, beer, cider and/or spirits, even if only occasionally, during pregnancy. The quantity of 
alcohol was classified as none; $<1 ; 1-2$ and $>2$ glasses per week. The cut-offs were defined $a$ priori.

Pesticides were categorized by type (i.e.: insecticides, herbicides, fungicides) and different categories were created depending on pesticide use alone or in combination with other pesticides. Further categories addressed the frequency of use $(<$ once a month $/ \geq$ once a month) and the location where pesticides were used (indoors, for gardening or outdoors, and on pets).

\section{Data analysis}

We estimated odds ratios (ORs) and 95\% confidence intervals (95\% CIs) by unconditional logistic regression (SAS version 9; SAS Institute Inc., Cary, NC, USA). The socioeconomic variables tested as potential confounders were: parental socio-professional category, maternal level of education, urban status of the area of residence, maternal age at child's birth, birth order, and the type of housing during pregnancy. They were tested to determine whether they met the empirical definition of confounding (i.e. independent association with both the exposure of interest and with Wilms' tumor). None of these variables was significantly associated with both, case-control status and the exposure. The final model included the matching variables (child's age and gender) and maternal age and urban status of the area of residence selected as potential surrogate confounders of the selection processes.

Spearman's $\tau$ statistic was used to calculate the correlation between parental exposures (i.e.: parental smoking, maternal use of household pesticides) in the three months before pregnancy and during pregnancy.

\section{Results}

After completion of the recruitment and selection processes, 117 case and 1100 control children were included.

Table 1 shows the main sociodemographic characteristics of the study sample. Case and control children and their mothers were generally similar, except that case children were more likely to be younger, to be first-born and to have younger mothers at the time of birth. The 
cases also lived in urban areas more often. More cases (68\%) than controls (46\%) were female.

Neither maternal smoking during pregnancy nor paternal smoking during preconception/pregnancy was associated with a risk of Wilms' tumor (ORs 1.1[95\% CI 0.71.8] and 1.1 [95\% CI 0.7-1.7], respectively) (Table 2). The estimates were similar when only one parent or both had reported smoking during the periconceptional period. No association was observed with maternal alcohol consumption during pregnancy (OR 1.2 [95\% CI 0.8 2.0]).

Maternal use of household pesticides during pregnancy was reported more frequently by case mothers (52.1\%) than control mothers (40.2\%). The most commonly used pesticides were insecticides (50.4\% of cases and $38.4 \%$ of controls) and they were mainly used alone. Herbicides and fungicides were rarely used and the mothers often also used insecticides.

The maternal use of any pesticide during pregnancy was associated with an increased risk of Wilms' tumor (OR 1.6 [95\% CI 1.1 - 2.3]). The use of any insecticide was associated with a risk of Wilms' tumor when the insecticide was used alone (OR 1.6 [95\% CI 1.1 - 2.4]) and when it was used in combination with other pesticides (OR 2.6 [95\% CI 1.2 - 5.7]). The association was stronger when mothers used insecticides more often than once a month (OR 1.9 [95\% CI $1.2-3.0])$.

Professional desinsectisation of the home during pregnancy was not associated with the risk of Wilms' tumor OR 1.0 [ 95\% CI 0.4 - 2.6]

The correlations between parental exposure in the three months before and during the index pregnancy were strong (Spearman's $~ 0.66$ for maternal smoking and 0.61 for maternal insecticide use).

\section{Discussion}

Our findings suggest that the maternal use of household pesticides during pregnancy may be associated with an increased risk of Wilms' tumor. The findings do not support an association with parental smoking or maternal alcohol consumption during the perinatal period.

With regard to maternal use of household pesticides during pregnancy, only two previous studies[15,24] have assessed the exposure as a potential risk factor. In line with our findings, 
a large study including more than 500 Wilms' tumor cases in the US and Canada [24] also found that pesticide use was associated with a modest increase in Wilms' tumor risk (ORs about 1.4). As was the case in our study, the study had limited ability to investigate associations with pesticides other than insecticides since the majority of the mothers who reported any pesticide use had used insecticides, either alone or combined with herbicides or fungicides. A US registry-based study [15], which included 300 case children, found a positive but non-significant association between Wilms' tumor and the use of household pesticides during pregnancy and the 2-year period prior to birth.

In our study, the association was stronger when pesticides were used more frequently. No association was observed with the professional disinsectation of the home, which could induce higher pesticide exposure. A German study [16] and a Brazilian study [28] showed positive yet non-significant associations with professional pesticide use in the periconceptional period. Olshan et al [14] found an association for a history of household insect and pest extermination (OR 2.2 [95\% CI 1.2-3.7]), but no dose-response relationship with the number of exterminations was evident. It is worth noticing that in our study the prevalence of professional extermination was low and the estimate was based in only six exposed cases.

The ANSES survey[22] described pesticide use of 1500 French representative households during the year 2014. Use of pesticide at least once in 2014 was reported by $75 \%$ of the households. In our study, $40 \%$ of the control mothers reported the use of pesticide at any time during pregnancy, which is lower than in the survey. This may be partly due to the fact that three quarters of the interviewees of the survey were men. It is unlikely that it reflects reduction of exposure to toxics during pregnancy since in our study maternal use of household pesticides was reported as frequently during pregnancy and before pregnancy. On the other hand, mothers may have underreported their past exposures and reporting bias cannot be ruled out.

Like in the ANSES survey, the pesticides most frequently used in our study were insecticides. Herbicides and fungicides were less frequently reported. In the ANSES report, the use of household pesticides tended to increase with the surface of the house, the parental age and the level of education. In our study, all these factors were considered as potential confounders.

The potential underlying mechanisms have yet to be elucidated. In our study we were not able to assess individual chemicals. The study performed by the ANSES found that the individual 
substances most frequently found in stocked products were pyrethroids (i.e cypermethrin and permethrin) (overall 23\%) followed by glyphosate (20\%) and fipronil (18\%). The IARC has considered that Permethrin is not classifiable as to its carcinogenicity to humans (Group 3)[29] since evidence from experimental animals was inadequate and there was no evidence from studies in humans. More recently, the US Environmental Protection Agency has classified permethrin as "likely to be carcinogenic to humans" by ingestion [30]. The most used herbicide, glyphosate, has been classed as "probably carcinogenic to humans” (Group 2A) in March 2015 by the IARC based on the review of about 1000 studies[21].

Pesticides are a heterogeneous group of compounds with diverse biological targets and modes of action. Consequently, their involvement in a common biological carcinogenicity pathway seems unlikely. However, childhood cancers are complex and multi-step diseases that are not mediated by a single biological pathway. Carcinogenicity may be the consequence of different mutagenic or immunotoxic properties of pesticides, which may impair different biological processes. Participants may have been exposed to multiple types of pesticides, whose interactions and cumulative effects have yet to be elucidated. Although our study focused on exposure during pregnancy, exposure is likely to have extended over a longer time period as shown by the correlation between time periods (preconception, pregnancy and childhood).

Our findings do not support an association between parental smoking during the periconceptional period and an increased risk of Wilms' tumor. Consistently with our findings, previous studies that assessed parental smoking during the perinatal period did not show any associations with Wilms' tumor, as summarized in a meta-analysis by Chu et al. [9] $(\mathrm{OR}=0.92[0.77-1.10])$.

Only three previous studies addressed maternal alcohol consumption during pregnancy $[5,16,18]$. Their findings are consistent with ours and do not observe an association with Wilms' tumor risk. However, it is to be noted that in two studies $[5,18]$ the estimates were based on very few exposed cases.

As was the case in previous interview-based research on this subject, our study was unable to assess exposure accurately. The self-reporting of pesticide exposure may have introduced classification bias. As in all case-control studies, over-reporting of exposure by cases may explain the positive associations. However, previous studies have found self-reported pesticide treatments and pesticide concentrations in dust to be consistent [31] and shown that 
parental agreement on pesticide exposures did not differ by case-control status [32], suggesting no differential recall in pediatric cancer case parents.

The parental self-reporting of smoking and alcohol consumption may also be subject to misclassification. Some studies suggest that social desirability may influence the selfreporting of substance abuse [33]. The harmful effects of maternal smoking during pregnancy are well known and case mothers may under-report the exposure with a view to denying any responsibility for their child's disease. In addition, the estimates of the association with paternal smoking may be biased if the information provided by the mother is inaccurate. In our study, the extent of the bias may be limited since, in the subset used for validation, the agreement between the maternal and paternal responses was high with regard to both ever smoking and number of cigarettes smoked per day[34]. Furthermore, the exposure prevalence in our control population seems to be representative of the source population. The French National Perinatal Survey in 2010 reported that 31\% of women had smoked before pregnancy but during pregnancy the percentage fell to $17 \%$ [34]. These results are similar to ours: $36 \%$ of the control mothers reported having smoked before pregnancy and 20\% during pregnancy. With regard to control fathers' smoking, the French Health Barometer surveys [35] reported that $48 \%$ of men aged between 26 and 34 years and 41\% of those aged between 35 and 44 years were daily smokers in 2010, which is consistent with our results (41\% of the control fathers aged between 26 and 34 years and 39\% of those aged between 35 and 44 years reported having smoked at least one cigarette during preconception).

Our study has major strengths. Case children were selected from the population-based French National Registry of Childhood Cancers, which has a high degree of exhaustiveness, and the overall participation rate for eligible cases was 91.5\%. Control selection was based on random generation of listed and unlisted telephone numbers and the participation rate was also high (85.5\%). Compared with the Perinatal Survey performed in France in 2010 [34], the control mothers were slightly older at the index child's birth. It has been suggested [36] that participation of younger mothers tend to be low among control families despite adequate sampling frame and satisfactory response rate among controls. Although maternal age is not thought to be related to Wilms tumor, all the analyses were adjusted on maternal age in an effort to account for this participation bias. The findings remained unchanged when sensitivity analyses excluding cases with a mobile phone only were conducted.

In conclusion, our French population-based study suggests an association between Wilms' tumor and maternal use of household pesticides during pregnancy. Large epidemiological 
studies with enhanced exposure characterization are difficult to organize because of the rarity of the disease and the lack of objective exposure measurements. However, until a better study can be designed, our findings provide additional reasons for advising pregnant women to limit pesticide exposure during the periconceptional period. Finally, in line with previous studies, our study brings no evidence of association between parental smoking around pregnancy or maternal alcohol consumption during pregnancy and the risk of Wilms' tumor. However, literature is still scarce and needs more studies.

\section{Grant sponsors:}

INSERM, the Ligue National Contre le Cancer (LNCC), the Fondation de France, the Fondation ARC, the Agence nationale de sécurité sanitaire de l'alimentation, de l'environnement et du travail (ANSES), the association Cent pour sang la vie, the Agence Nationale de la Recherche (ANR), the Institut National du Cancer (INCa) and the Canceropôle Ile de France, and Investment for the future (ANR-10-COHO-0009 grant)

\section{Acknowledgments:}

The authors are grateful to: Noureddine Balegroune, Sofiène Ben Salha and the team of clinical research associates who contributed to the recruitment of the cases; the team of the French national registry of childhood cancer, and Christophe David and the team of interviewers (Institut IPSOS), who interviewed the cases and controls. The authors would also like to thank all of the Societé Française de lutte contre les Cancers de l'Enfant et de l’Adolescent (SFCE) principal investigators, Claire Berger (Centre Hospitalier Universitaire, Saint- Etienne), Christophe Bergeron (IHOPe, Lyon), Pascal Chastagner (Centre Hospitalier Universitaire, Nancy), Patrick Boutard (Centre Hospitalier Régional Universitaire, Caen), Gérard Couillault (Hôpital d’Enfants, Dijon), François Demeocq (Hôpital HôtelDieu,Clermont-Ferrand), Virginie Gandemer (Centre Hospitalier Universitaire Hôpital Sud, Rennes), Jean-Pierre Lamagnere (Centre Gatien de Clocheville, Tours), Françoise Lapierre (Centre Hospitalier Universitaire Jean Bernard, Poitiers), Patrick Lutz (Hôpital de Hautepierre, Strasbourg), Stéphane Ducassou (Hôpital Arnaud de Villeneuve, Montpellier), Françoise Mechinaud (Hôpital Mère et Enfants, Nantes), Gerard Michel (Hôpital La Timone, Marseille), Frederic Millot (Centre Hospitalier Universitaire Jean Bernard, Poitiers), Martine 
Munzer (American Memorial Hospital, Reims), Brigitte Nelken (Hôpital Jeanne de Flandre, Lille), Helène Pacquement (Institut Curie, Paris), Brigitte Pautard (Centre Hospitalier Universitaire, Amiens), Alain Pierre-Kahn (Hôpital Enfants Malades, Paris), Emmanuel Plouvier (Centre Hospitalier Regional, Besançon), Xavier Rialland (Centre Hospitalier Universitaire, Angers), Alain Robert (Hôpital des Enfants, Toulouse), Stephanie Haouy (Hôpital Arnaud de Villeneuve, Montpellier), Christine Soler (Fondation Lenval, Nice), JeanPierre Vannier (Hôpital Charles Nicolle, Rouen), Pascal Chastagner (Centre Hospitalier Universitaire, Nancy), Christophe Piguet (Centre Hospitalier Regional Universitaire, Limoges, Philippe Colombat (Centre Gatien de Clocheville,Tours), Nicolas Sirvent (Hôpital Arnaud de Villeneuve, Montpellier), François Doz (Institut Curie, Paris), Herve Rubie (Hôpital des Enfants, Toulouse), Marilyne Poiree (Fondation Lenval, Nice), Dominique Plantaz (Centre Hospitalier Universitaire, Grenoble), Philippe le Moine (Hôpital Morvan, Brest).

Bibliography

[1] B. Lacour, A. Guyot-Goubin, S. Guissou, S. Bellec, E. Désandes, and J. Clavel, "Incidence of childhood cancer in France: National Children Cancer Registries, 20002004,” Eur. J. Cancer Prev., vol. 19, no. 3, pp. 173-181, 2010.

[2] A. Guyot-Goubin et al., “Childhood cancer survival in France, 2000-2008,” Eur. J. Cancer Prev., vol. 23, no. 5, pp. 449-457, Sep. 2014.

[3] R. H. Scott, C. A. Stiller, L. Walker, and N. Rahman, "Syndromes and constitutional chromosomal abnormalities associated with Wilms tumour,” J. Med. Genet., vol. 43, no. 9, pp. 705-715, 2006.

[4] M. Carell and J. Children, "Malformations, genetic abnormalities, and Wilms Tumor,” no. April 2013, pp. 140-144, 2009.

[5] S. E. Puumala, J. T. Soler, K. J. Johnson, and L. G. Spector, "Birth characteristics and Wilms tumor in Minnesota,” Int. J. Cancer, vol. 122, no. 6, pp. 1368-1373, 2008.

[6] A. E. Altmann, J. L. Halliday, and G. G. Giles, “Associations between congenital malformations and childhood cancer. A register-based case-control study,” Br. J. Cancer, vol. 78, no. 9, pp. 1244-1249, 1998. 
[7] N. E. Breslow, J. Olson, J. Moksness, J. B. Beckwith, and P. Grundy, “Familial Wilms’ tumor: A descriptive study,” Med. Pediatr. Oncol., vol. 27, no. 5, pp. 398-403, 1996.

[8] G. M. Marshall et al., “The prenatal origins of cancer,” Nat. Rev. Cancer, vol. 14, no. 4, pp. 277-289, 2014.

[9] A. Chu et al., "Wilms' tumour: A systematic review of risk factors and meta-analysis," Paediatr. Perinat. Epidemiol., vol. 24, no. 5, pp. 449-469, 2010.

[10] IARC, “Monograph - Tobacco smoking,” 2010.

[11] IARC, "IARC Monographs on the evaluationof Carcinogenic Risk to Humans. VOLUME 100E. Second-hand Tobacco Smoke.,” 2012.

[12] IARC, "IARC Monographs on the Evaluation of Carcinogenic Risks to Humans VOLUME 96 Alcohol Consumption and Ethyl Carbamate,” 2010.

[13] C. Hansen, I. Asmussen, and H. Autrup, “Detection of carcinogen-DNA adducts in human fetal tissues by the32P-postlabeling procedure,” in Environmental Health Perspectives, 1993, vol. 99, pp. 229-231.

[14] A. F. Olshan et al., "Risk factors for Wilms tumor: Report from the national Wilms tumor study,” Cancer, vol. 72, no. 3, pp. 938-944, Aug. 1993.

[15] J. Tsai, W. E. Kaye, and F. J. Bove, “Wilms' tumor and exposures to residential and occupational hazardous chemicals,” Int. J. Hyg. Environ. Health, vol. 209, no. 1, pp. 57-64, 2006.

[16] J. Schüz, U. Kaletsch, R. Meinert, P. Kaatsch, and J. Michaelis, "High birth weight and other risk factors for Wilms tumour: Results of a population-based case-control study,” Eur. J. Pediatr., vol. 160, no. 6, pp. 333-338, Jun. 2001.

[17] D. Pang, R. Mcnally, and J. M. Birch, "Parental smoking and childhood cancer : results from the United Kingdom Childhood Cancer Study,” Br. J. Cancer, vol. 88, pp. 373381, 2003.

[18] G. R. Bunin, S. Kramer, O. Marrero, and A. T. Meadows, "Gestational Risk Factors for Wilms’ Tumor: Results of a Case-Control Study,” Cancer Res., vol. 47, no. 11, pp. 2972-2977, 1987.

[19] J. E. Heck et al., "Fetal programming and Wilms tumor,” Pediatr. Blood Cancer, vol. 
66, no. 1, pp. 1-11, 2019.

[20] R. M. Whyatt et al., "Contemporary-use pesticide in personal air samples during pregnancy and blood samples at delivery among urban minority mothers and newborns,” Environ. Health Perspect., vol. 111, no. 5, pp. 749-756, 2003.

[21] E. M. Ostrea et al., "Combined analysis of prenatal (maternal hair and blood) and neonatal (infant hair, cord blood and meconium) matrices to detect fetal exposure to environmental pesticides,” Environ. Res., vol. 109, no. 1, pp. 116-122, Jan. 2009.

[22] International Agency for Research on cancer, “Occupational exposures in insecticide application, and some pesticides,” 1991.

[23] M. A. Cooney, J. L. Daniels, J. A. Ross, N. E. Breslow, B. H. Pollock, and A. F. Olshan, "Household pesticides and the risk of Wilms tumor," Environ. Health Perspect., vol. 115, no. 1, pp. 134-137, Jan. 2007.

[24] P. Kristensen, A. Andersen, L. M. Irgens, A. S. Bye, and L. Sundheim, "Cancer in offspring of parents engaged in agricultural activities in Norway: Incidence and risk factors in the farm environment,” Int. J. Cancer, vol. 65, no. 1, pp. 39-50, Jan. 1996.

[25] E. Steliarova-Foucher, C. Stiller, B. Lacour, and P. Kaatsch, "International classification of childhood cancer, third edition,” Cancer, vol. 103, no. 7, pp. 14571467, Feb. 2005.

[26] L. Orsi et al., "Parental smoking, maternal alcohol, coffee and tea consumption during pregnancy, and childhood acute leukemia: the ESTELLE study,” Cancer Causes Control, 2015.

[27] H. D. Bailey et al., "Parental smoking, maternal alcohol, coffee and tea consumption and the risk of childhood brain tumours: the ESTELLE and ESCALE studies (SFCE, France),” Cancer Causes Control, vol. 28, no. 7, pp. 719-732, 2017.

[28] C. R. Sharpe et al., "Parental exposures to pesticides and risk of wilms' tumor in Brazil,” Am. J. Epidemiol., vol. 141, no. 3, pp. 210-217, Feb. 1995.

[29] R. C. Lewis et al., "Urinary biomarkers of exposure to insecticides, herbicides, and one insect repellent among pregnant women in Puerto Rico,” Environ. Heal. A Glob. Access Sci. Source, vol. 13, no. 1, p. 97, Dec. 2014. 
[30] G. R. Bunin, E. Ward, S. Kramer, C. A. Rhee, and A. T. Meadows, "Neuroblastoma and parental occupation.,” Am. J. Epidemiol., vol. 131, no. 5, pp. 776-80, May 1990.

[31] N. C. Deziel et al., “Associations between self-reported pest treatments and pesticide concentrations in carpet dust,” Environ. Heal. A Glob. Access Sci. Source, vol. 14, no. 1, 2015.

[32] J. L. Daniels et al., "Residential pesticide exposure and neuroblastoma,” Epidemiology, vol. 12, no. 1, pp. 20-27, Jan. 2001.

[33] D. R. Groh, J. R. Ferrari, and L. A. Jason, “Self-reports of substance abusers: The impact of social desirability on social network variables,” J. Groups Addict. Recover., vol. 4, no. 1-2, pp. 51-61, 2009.

[34] B. Blondel and M. Kermarrec, "Enquête nationale périnatale - Les maternités en 2010 et leur évolution depuis 2003,” Bur. santé la Popul. DREES, p. 81, 2011.

[35] Santé Publique France, “Consomations d’alcool et de tabac durant la grossesse. Baromètre Santé 2017,” 2017. 
Table 1 Socio-demographic characteristics of the study population

\begin{tabular}{|c|c|c|c|c|}
\hline & \multicolumn{2}{|c|}{ Cases $(n=117)$} & \multicolumn{2}{|c|}{ Controls $(\mathrm{n}=1100)$} \\
\hline & $\mathrm{n}$ & $\%$ & $\mathrm{n}$ & $\%$ \\
\hline \multicolumn{5}{|l|}{ Age } \\
\hline$<2$ years & 35 & 29.9 & 318 & 28.9 \\
\hline $2-3$ years & 36 & 30.8 & 287 & 26.1 \\
\hline $4-5$ years & 29 & 24.8 & 229 & 20.8 \\
\hline $6-7$ years & 12 & 10.3 & 136 & 12.4 \\
\hline $8-10$ years & 5 & 4.3 & 130 & 11.8 \\
\hline \multicolumn{5}{|l|}{ Gender } \\
\hline Girl & 68 & 58.1 & 503 & 45.7 \\
\hline Boy & 49 & 41.9 & 597 & 54.3 \\
\hline \multicolumn{5}{|l|}{ Birth-order } \\
\hline Firstborn & 59 & 50.4 & 439 & 39.9 \\
\hline Second or more & 58 & 49.6 & 661 & 60.1 \\
\hline \multicolumn{5}{|c|}{ Urban status of the area of residence (inhabitants) } \\
\hline$<5,000$ & 38 & 32.5 & 429 & 39.0 \\
\hline $5,000-99,999$ & 23 & 19.7 & 209 & 19.0 \\
\hline $100,000-1,999,999$ & 30 & 25.6 & 221 & 20.1 \\
\hline Paris urban unit & 25 & 21.4 & 237 & 21.5 \\
\hline Missing or unspecified & 1 & 0.9 & 4 & 0.4 \\
\hline \multicolumn{5}{|l|}{ Maternal education } \\
\hline Less than secondary & 27 & 23.1 & 276 & 25.1 \\
\hline Secondary & 24 & 20.5 & 246 & 22.4 \\
\hline Tertiary & 66 & 56.4 & 578 & 52.5 \\
\hline \multicolumn{5}{|l|}{ Maternal age at index birth } \\
\hline$<25$ years & 20 & 17.1 & 106 & 9.6 \\
\hline $25-29$ years & 49 & 41.9 & 324 & 29.5 \\
\hline $30-34$ years & 36 & 30.8 & 400 & 36.4 \\
\hline$\geq 35$ years & 12 & 10.3 & 269 & 24.5 \\
\hline Missing or unspecified & 0 & 0.0 & 1 & 0.1 \\
\hline
\end{tabular}


Table 2 Parental smoking in the periconceptional period, maternal alcohol consumption during pregnancy and the risk of Wilms' tumor in children.

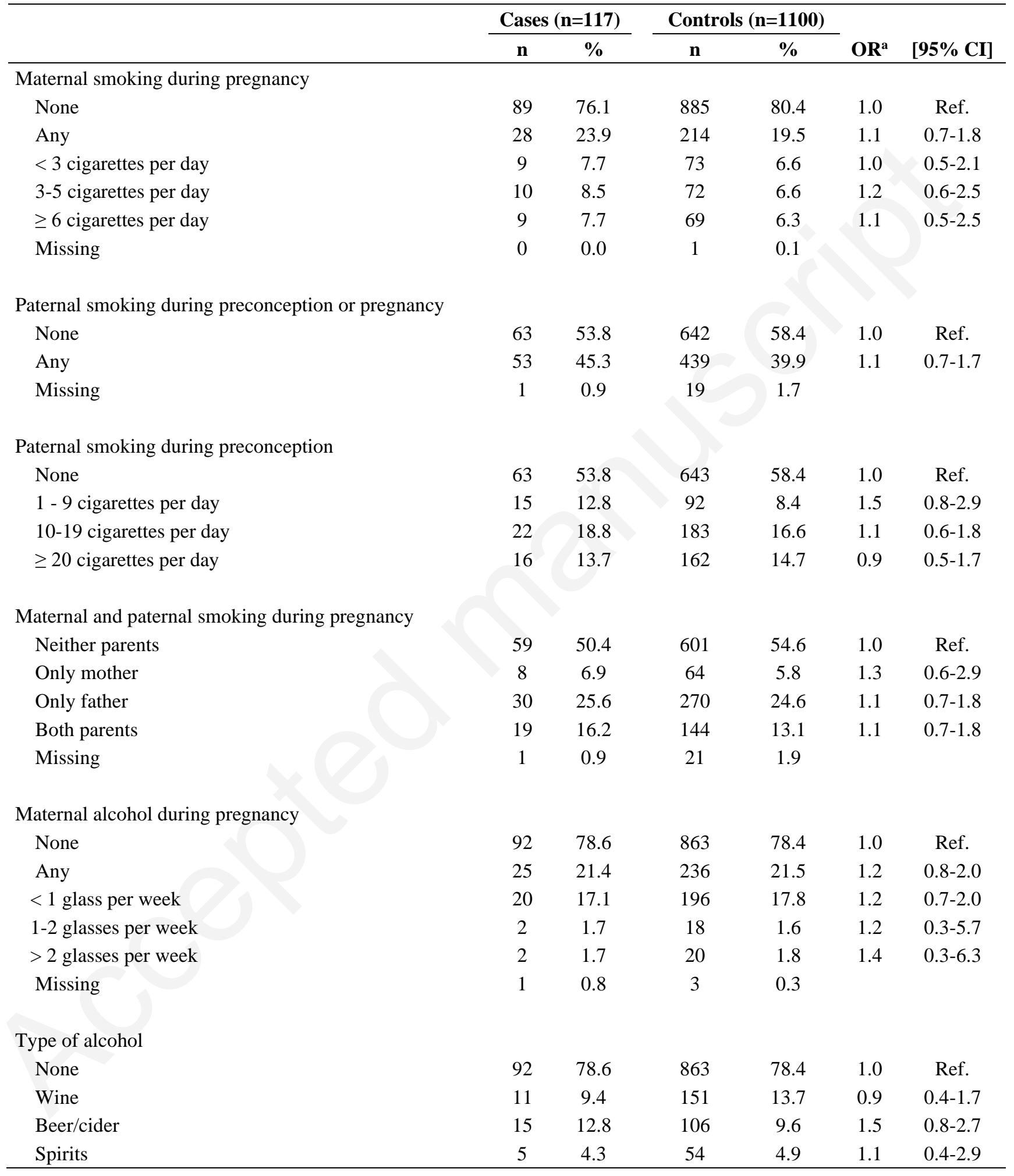

a Odds ratios (OR) and $95 \%$ confidence intervals (95\%CI) estimated by logistic regression models adjusted for children age and sex, maternal age and urban status of the area of residence 
Table 3: Maternal use of household pesticides during pregnancy and the risk of Wilms' tumor in children

\begin{tabular}{|c|c|c|c|c|c|c|}
\hline & \multicolumn{2}{|c|}{ Cases $(n=117)$} & \multicolumn{2}{|c|}{ Controls $(\mathrm{n}=1100)$} & \multirow[t]{2}{*}{$\mathrm{OR}^{\mathrm{a}}$} & \multirow[t]{2}{*}{$95 \% \mathrm{CI}$} \\
\hline & $\mathrm{n}$ & $\%$ & $\mathrm{n}$ & $\%$ & & \\
\hline \multicolumn{7}{|l|}{$\begin{array}{l}\text { Use of any pesticide during } \\
\text { pregnancy }\end{array}$} \\
\hline None & 56 & 47.9 & 635 & 57.7 & 1.0 & Reference \\
\hline Any pesticide & 61 & 52.1 & 442 & 40.2 & 1.6 & {$[1.1-2.3]$} \\
\hline Missing & 0 & & 23 & 2.1 & & \\
\hline \multicolumn{7}{|l|}{ Type of pesticide used } \\
\hline None & 56 & 47.9 & 635 & 57.7 & 1.0 & Reference \\
\hline Any insecticide & 59 & 50.4 & 422 & 38.4 & 1.7 & {$[1.1-2.6]$} \\
\hline Any herbicide & 5 & 4.3 & 34 & 3.1 & 1.3 & {$[0.5-3.6]$} \\
\hline Any fungicide & 7 & 6.0 & 32 & 2.9 & 2.1 & {$[0.8-4.9]$} \\
\hline \multicolumn{7}{|l|}{ Joint use of types of pesticides } \\
\hline None & 56 & 47.9 & 635 & 57.7 & 1.0 & Reference \\
\hline Only insecticides & 49 & 41.9 & 374 & 34.0 & 1.6 & {$[1.1-2.4]$} \\
\hline Only herbicides & 0 & & 6 & 0.5 & * & \\
\hline Only fungicides & 2 & 1.7 & 14 & 1.3 & 1.5 & {$[0.3-7.2]$} \\
\hline Insecticides + other pesticides & 10 & 8.5 & 44 & 4.0 & 2.6 & {$[1.2-5.7]$} \\
\hline \multicolumn{7}{|l|}{ Frequency of insecticide use } \\
\hline No use of any pesticides & 56 & 47.9 & 635 & 57.7 & 1.0 & Reference \\
\hline$<$ Once a month & 18 & 15.4 & 171 & 15.5 & 1.3 & {$[0.8-2.4]$} \\
\hline$\geq$ Once a month & 39 & 33.3 & 241 & 21.9 & 1.9 & {$[1.2-3.0]$} \\
\hline \multicolumn{7}{|l|}{ Type of insecticide use } \\
\hline No use of any pesticides & 56 & 47.9 & 635 & 57.7 & 1.0 & Reference \\
\hline Indoor use & 42 & 35.9 & 330 & 30.0 & 1.4 & {$[0.9-2.2]$} \\
\hline Gardening of outdoor use & 11 & 9.4 & 45 & 4.1 & 2.7 & {$[1.3-5.6]$} \\
\hline For pets & 22 & 18.8 & 158 & 14.4 & 1.4 & {$[0.8-2.3]$} \\
\hline Professional disinsectisation & 6 & 5.1 & 44 & 4.0 & 1.0 & {$[0.4-2.6]$} \\
\hline
\end{tabular}

a Odds ratios (OR) and $95 \%$ confidence intervals $(95 \% \mathrm{CI})$ estimated by logistic reg ression models adjusted for children age and sex, maternal age and urban status of the area of residence

* Too few cases to fit model 